Mark V. Williams, MD

Editor-in-Chief
Competing interest: M.V.W. is the editor of the Journal of Hospital Medicine and he will not benefit financially from the arrangement to have POEMs published in the Journal. The owner of InfoPOEMs, Wiley Publishing, is also the publisher of this journal. The Society of Hospital Medicine owns the Journal of Hospital Medicine.

\section{POEMs to Help You at the Point of Care}

$\mathrm{n}$ addition to marking my initial transition from student to physician, the commencement address by the medical informatics pioneer, Larry Weed, is my most enduring memory of medical school graduation. A provocative thinker in the field of decision support and structured medical records, Weed was credited by my teachers with developing the organized SOAP note. During his address he depressingly equated all the knowledge we had digested during the preceding mentally strenuous 4 years to shoveling a mountain of manure with a teaspoon. Although I agreed that some of the information I learned seemed to lack relevance (still don't know why I needed to learn the details of the Krebs cycle), as I began caring for patients as an intern, I found that much of it mattered. As I launched into residency training, I also discovered that lifelong learning would be a perpetual component of my medical career.

Despite becoming a passionate advocate of practicing evidence-based medicine (EBM), I also recognized the impossibility of "keeping up" with the medical literature, given the relentless arrival of journals in the mail. Learning all the evidence is impossible, so we must develop information management skills and allow others to help us in identifying, reviewing, and summarizing salient and valid clinical information. ${ }^{1}$ One of my vital goals as editor of the Journal of Hospital Medicine is to ensure we provide our readers with useful clinical information that is concise, easily digested, and usable.

To that end we are introducing Patient-Oriented Evidence that Matters ${ }^{\mathrm{TM}}$, or POEMs. As described on the InfoPOEMs website (www.infopoems.com), "POEMs have to meet three criteria:

- They address a question that we face as clinicians.

- They measure outcomes that we and our patients care about: symptoms, morbidity, quality of life, and mortality.

- They have the potential to change the way we practice."

We are not the first journal to do this and join the company of the British Medical Journal and the Cleveland Clinic Journal of Medicine. ${ }^{2,3}$ Staff physicians at InfoPOEMs screen more than 100 peer-reviewed medical journals for relevant articles that practicing physicians can use at the point of care, the patient. A trained physician "poet" then summarizes selected articles in a standardized manner into a POEM. A POEM begins with a clinical question and then provides a bottom line answer from a recently published journal article. This is followed by a structured abstract that includes the study design and setting, followed by a synopsis of the article. 
We will start with at least 2 POEMs per issue focused on clinical topics relevant to hospitalists. Soon, an experienced academic hospitalist and knowledgeable expert in EBM, Dr. Jennifer Kleinbart, will be writing POEMs for hospitalists. We look forward to your opinions about whether we should increase this content. Let me know.

\section{REFERENCES}

1. Slawson DC, Shaughnessy AF. Teaching evidence-based medicine: should we be teaching information management instead? Acad Med. 2005;80:685-689.

2. Smith R. A POEM a week for the BMJ. Br Med J. 2002;325: 983.

3. POEMs: Keeping up with clinical research that can change your practice. Cleve Clin J Med. 2004;71:222. 